\title{
The abnormalities in the p53/p21WAF1 pathway have a significant role in the pathogenesis and progression of gastrointestinal stromal tumors
}

\author{
YEH-PIN CHOU ${ }^{1}$, JUI-WEI LIN ${ }^{2}$, CHIH-CHI WANG ${ }^{3}$, YI-CHUN CHIU ${ }^{1}$, CHAO-CHENG HUANG $^{2}$, \\ SENG-KEE CHUAH ${ }^{1}$, MING-HONG TAI ${ }^{4}$, LI-NA YI ${ }^{1}$, CHUAN-MO LEE $^{1}$, \\ CHI-SIN CHANGCHIEN ${ }^{1}$ and TSUNG-HUI HU ${ }^{1}$
}

\begin{abstract}
${ }^{1}$ Division of Gastroenterology, Department of Internal Medicine; Departments of ${ }^{2}$ Pathology and ${ }^{3}$ Surgery, Chang Gung Memorial Hospital - Kaohsiung Medical Center, Chang Gung University College of Medicine, No. 123, Ta-Pei Road, Niao-Sung Hsiang, Kaohsiung Hsien 833, Kaohsiung; ${ }^{4}$ Department of Medical Education and Research, Kaohsiung Veterans General Hospital, No. 386, Ta-Chung 1st Road, Kaohsiung 813, Taiwan
\end{abstract}

Received July 6, 2007; Accepted August 21, 2007

\begin{abstract}
To elucidate the prognostic role and relationship of the p53/p21/PCNA pathway in gastrointestinal stromal tumors (GISTs), a total of 167 resected gastric and small intestinal CD117-positive stromal tumor specimens were collected from January 1987 to December 2000. Immunohistochemical studies were performed on the paraffin sections with antibodies of p53, p21/WAF1, proliferating cell nuclear antigen (PCNA) and Ki-67. The immunoreactivity of four markers was recorded by labeling index (LI, \%) for clinicopathologic and survival correlation. The labeling index was 0-83\% for $\mathrm{p} 53,0-81 \%$ for $\mathrm{p} 21 / \mathrm{WAF} 1,0-33 \%$ for $\mathrm{Ki}-67$ and $12-92 \%$ for PCNA. Completely negative immunostaining $(\mathrm{LI}<1 \%)$ was found in $54.5 \%$ of $\mathrm{p} 53,25.8 \%$ of $\mathrm{p} 21 / \mathrm{WAF} 1$ and $44.3 \%$ of Ki-67. The LI of four markers strongly correlate with each other $(\mathrm{p}<0.05)$. Furthermore, the LI of all four markers positively correlate to microscopic tumor mitotic counts $(\mathrm{p}<0.05)$. Only the LI of p53 and PCNA positively correlate to tumor sizes. Tumors with non-spindle cell type (versus spindle cell) and high cellular pleomorphism (versus low) exhibited a higher p53, p21/WAF1 and PCNA LI $(\mathrm{p}<0.05)$. Increased NIH risk significantly correlates to increased p53, PCNA and Ki-67 $(\mathrm{p}<0.05)$ LI. Survival analysis indicated that a large tumor size $(\geq 5 \mathrm{~cm}, \mathrm{p}=0.003)$, increased tumor mitosis
\end{abstract}

Correspondence to: Dr Tsung-Hui Hu, Division of Gastroenterology, Department of Internal Medicine, Chang Gung Memorial Hospital - Kaohsiung Medical Center, Chang Gung University College of Medicine, No. 123, Ta-Pei Road, Niao-Sung Hsiang, Kaohsiung Hsien 833, Taiwan

E-mail:dr.hu@msa.hinet.net

Key words: gastrointestinal stromal tumors (GISTs), p53, p21/ WAF1, proliferating cell nuclear antigen, Ki-67, prognosis
( $\geq 5 / 50$ HPF, $\mathrm{p}<0.001)$, high NIH risk $(\mathrm{p}<0.001)$, non-spindle cell type $(\mathrm{p}=0.024)$, high p53 LI $(\mathrm{p}<0.001)$, high $\mathrm{p} 21 / \mathrm{WAF} 1$ LI $(\mathrm{p}=0.007)$, high Ki-67 LI $(\mathrm{p}<0.001)$ and high PCNA LI $(\mathrm{p}<0.001)$ were prognostic factors for poor disease-free survival. Independent factors are tumor size, NIH risk, p53 and p21/WAF1 LI. We demonstrated the first evidence of the linear relationship and prognostic role of the p53/p21/PCNA pathway in gastrointestinal stromal tumors. Abnormalities of the p53/p21WAF1 pathway lead to increased proliferating states, thereby triggering the progression of GISTs.

\section{Introduction}

Gastrointestinal stromal tumors are interstitial tumors arising in the wall of the gastrointestinal tract. Gastrointestinal stromal tumors have strong morphological similarities in their pathological features, but have heterogeneous immunophenotype and biological behavior (1). The gastric and intestinal smooth muscle tumors in the older data largely would be classified as GISTs by immunohistochemical methods $(2,3)$. Concerning prognosis, many studies have established clinicopathological correlations, yet the criteria claimed to predict the prognosis remain vague. Although the proliferating activity in terms of the mitotic count is generally accepted as a prognostic indicator (4), other gross and histologic parameters are reported to influence the course of disease, such as tumor size $(4,5)$, cellular density $(6,7)$, predominant cell type $(6,8)$, neurnal or muscular component (9), necrosis (10) and histological grades (6). It was suggested that in addition to the use of the KIT expression in the diagnosis of GISTs, c-kit mutation may correlate to the malignant potential of GISTs $(11,12)$. Fletcher et al (13), according to the consensus approach at the National Institute of Health in 2001, recommended the use of risk assessment in predicting GISTs behavior, in preference to trying to draw a sharp line between benign and malignant lesions. They categorized GISTs into 4 groups as very low, low, intermediate and high risk. 
Molecular markers by immunohistochemical studies dealing with a proliferating index such as Ki-67 (14-17), a proliferating cell nuclear antigen (PCNA) $(15,16)$ and a tumor suppressor gene p53 (17-19) were applied with encouraging results. The alteration of certain cell cycle regulatory proteins was implicated in the pathogenesis and tumor progression of various kinds of tumors. Numbers of down-stream genes containing wild-type p53 binding sequences were identified. Among these, p21/WAF1 is the most important one. P21/ WAF1 is a nuclear protein and induces cell cycle arrest in the G1- and G2-phases by inhibiting cyclin/CDK complexes and the PCNA function (20). The PCNA and p21/WAF1 actively interact in the response to DNA damage. After a UV challenge, p21/WAF1 and PCNA co-localize in the nucleus and become detergent-insoluble, due to a tight link to DNA (21). P21/ WAF1 can be activated in p53-dependent and -independent manner (22). Cells lacking a functional p53 express a very low level of $\mathrm{p} 21 / \mathrm{WAF} 1$ and the $\mathrm{p} 21 / \mathrm{WAF} 1$ promoter contains a p53-binding site, suggesting that the expression of p21/ WAF1 depends on a p53 function (22-24). However, p21/ WAF1 can be inducible in p53-null cells, showing that the expression of p21/WAF1 can also be induced by p53independent pathways $(22,25,26)$.

However, recent studies reflect a limited experience in the expression and prognostic role of p21/WAF1 in GISTs $(18,27)$. There was no linear linkage between p53/p21/ PCNA pathways in the previous literatures. In this study, we examined by an immunohistochemical technique the possible role of p53/p21/PCNA pathways, based on a relatively large sample size of 167 human GISTs (including the stomach and small intestine) after resection and elucidated their correlation with clinicopathological features. We then evaluated the prognostic factors for disease-free survival and overall survival analysis in GIST patients with at least 5 years of follow-up and found that patients with a positive expression of p21/WAF1 in GISTs had a shorter disease-free survival after resection, which is a novel finding.

\section{Materials and methods}

Collection of clinical samples. A total of 167 surgically resected gastric and small intestinal stromal tumor specimens (CD117+) were collected at Kaohsiung Chang Gung Memorial Hospital from January 1986 to December
2000. Patients with tumors which could not be completely resected or patients with evident metastasis on diagnosis were excluded. All of the tumors were obtained from curative resection. The diagnosis of malignant potential of a tumor was based on the index of NIH risk categories (very low risk, low risk, intermediate risk and high risk) according to tumor mitosis and size (13). The closing date of the follow-up was December 31, 2005. Patients who died due to post-surgical complications were excluded from this study. In each case, all slides were reviewed and the following histological parameters were regarded and recorded by pathologist: a) predominant cell type: spindle or non-spindle (epithelioid or mixed); b) nuclear pleomorphism (mild, moderate or high). The cell type was categorized as being predominantly spindle ( $>75 \%$ of the tumor), epithelioid ( $>75 \%$ of the tumor), or mixed if both the spindle and epithelioid components occupied $>25 \%$ of the tumor. Nuclear pleomorphism is defined as a variation in the nuclear size and shape and was judged to be mild $(<10 \%)$, moderate $(10-30 \%)$, or severe $(>30 \%)$.

Immunohistochemistry. Tissue specimens were maintained in formaldehyde-fixed, paraffin-embedded blocks. Sections stained with hematoxylin and eosin (H\&E) were also reviewed. The paraffin sections from specimens were deparaffinized, blocked with $3 \%$ hydrogen peroxide for 10 min and subjected to antigen retrieval with microwave in $0.01 \mathrm{M}$ citrate buffer for 15 min. The slides were then washed twice with PBS, incubated with primary antibodies of CD117, CD34, smooth muscle actin (SMA), S-100, desmin, p21/WAF1, p53, Ki-67 and PCNA for $30 \mathrm{~min}$ each, then examined with a peroxidase conjugate using the polymer detection system (Zymed Cat. No. 87-89431) for $30 \mathrm{~min}$. Specific details of the immunohistochemical condition used for each are shown in Table I. The antibody staining was visualized with 3,3-diaminobenzidine tetrahydrochloride (DAB; Sigma, St. Louis, MO) in 0.1 M Tris $\mathrm{pH} 7.2$, containing $0.01 \% \mathrm{H}_{2} \mathrm{O}_{2}$. The section slides were counter-stained with Gill's hematoxylin, dehydrated and mounted.

Scoring of immunostaining. The markers (CD117, CD34, SMA, desmin and S100) in the tumor cells on each slide were expressed as a negative or positive stain by estimating the number of positive tumor cells. Negative was defined as $<10 \%$ of area with staining. The labeling index (LI) (\%) of nuclear

Table I. Sources of antibodies and ratio of dilutions used in this study.

\begin{tabular}{lcc}
\hline Antibodies & Source & Dilution \\
\hline CD117 monoclonal & Dako M7140 Clone104D & $1: 50$ \\
CD34 monoclonal & Dako M7161 CloneQBEnd10 & $1: 200$ \\
Desmin monoclonal & Novocastra NCL-DES-DERII Clone DE-R-11 & $1: 100$ \\
Smooth muscle actin monoclonal & Novocastra NCL-SMA Cloneasm & $1: 50$ \\
S-100 polyclonal & Novocastra NCL-S100p & $1: 1500$ \\
p53 monoclonal & Dako, clone: PAb240 & $1: 200$ \\
p21 monoclonal & Zymed, clone EA10 & $1: 100$ \\
Ki-67 monoclonal & Dako MIB1 & $1: 50$ \\
PCNA monoclonal & Dako M0879 & $1: 5$ \\
\hline
\end{tabular}


A
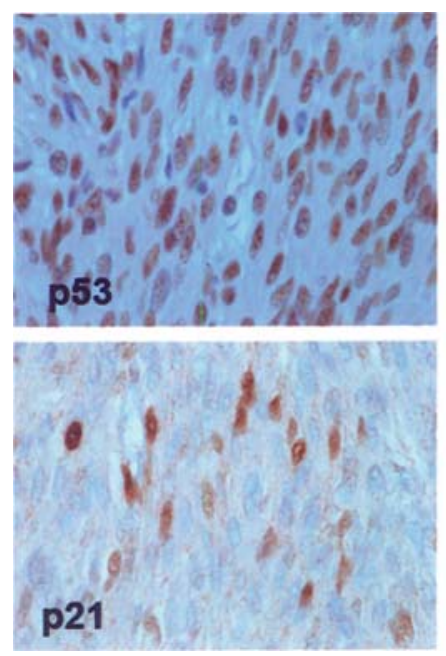
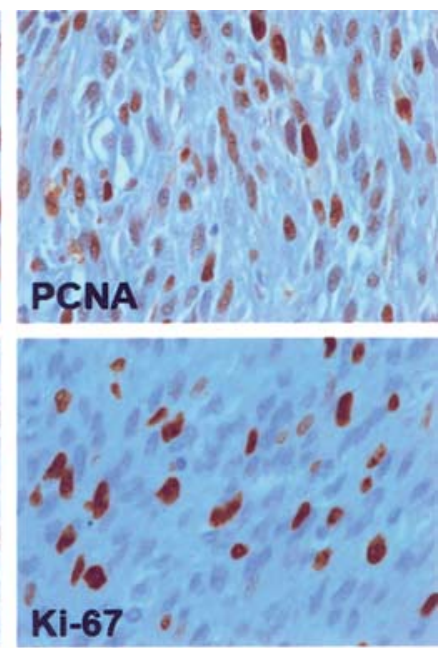

B
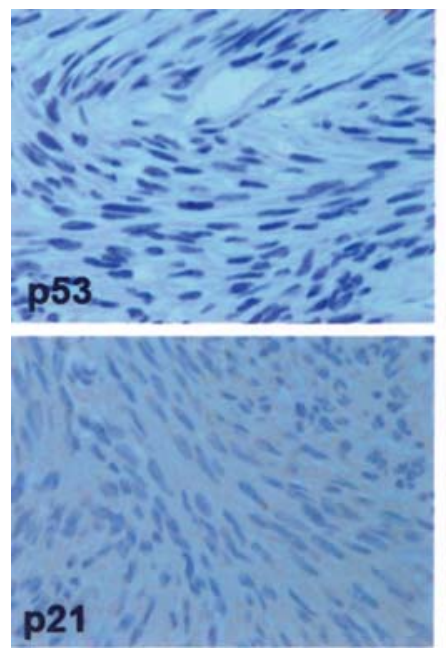
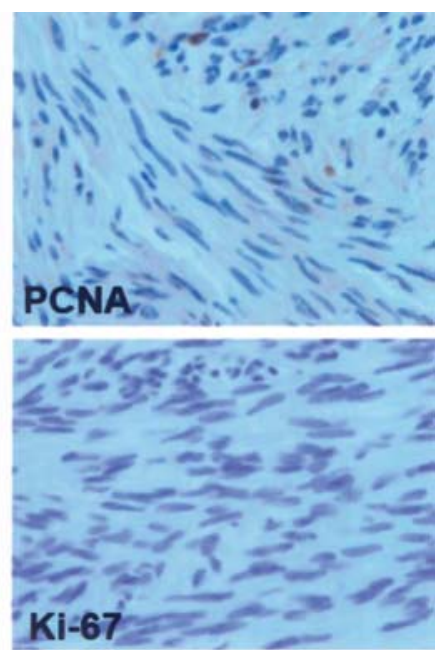

Figure 1. Representive figures of the immunohistochemical studies of p53, p21/WAF1, PCNA and Ki-67 in the two GISTs. (A) Epithelioid type tumor in case 1 showed a high p53, p21/WAF1, PCNA and Ki-67 expression in patients who had disease recurrence 7 months after surgery. (B) In contrast, spindle type tumor in case 2 exhibited a low p53, p21/WAF1, PCNA and Ki-67 expression in patients who survived more than 5 years after curative surgery.

p21/WAF1, p53, Ki-67 and PCNA was calculated in percentage by two pathologists for each case. The percentage of the nuclear p21/WAF1, p53, Ki-67 and PCNA-labeled tumor cells (from counting 1,000 cells) was calculated three times for each tumor and an average of the three counts was used for subsequent analyses. There was disagreement between proportional scores given by the two assessors in $<5 \%$ of the cases. The cases with discrepant scores were re-assessed to produce final scores. Subsequently, the correlation between LI and clinicopathological parameters of GISTs was statistically analyzed. Because of different immunostaining patterns of markers, the labeling index of the nuclear p21/WAF1, p53, Ki-67 and PCNA were further divided into two groups (by ROC curve) as high or low expression for survival analysis.

Statistical methods. The age and tumor size were expressed as mean \pm standard deviation. Comparisons between groups of independent samples were assessed by the Mann-Whitney U or Kruskal-Wallis H test. Associations between categorical variables were assessed using the Chi-square test. The correlation between continuous variables was determined by the Spearman's rank correlation test. Survival rates were calculated by the Kaplan-Meier method and the difference in survival was compared with the log-rank test. The influence of various clinicopathological features on survival was assessed by Cox's proportional hazard model. $\mathrm{P}<0.05$ was considered statistically significant.

\section{Results}

Clinicopathological information. A total of 167 cases of CD117 (+) GISTs were included comprising of 81 males and 86 females, aged from 30 to 80 years (mean: $57.2 \pm 12.2$ years) and tumor size from 1 to $26 \mathrm{~cm}$ (mean: $7.4 \pm 4.4 \mathrm{~cm}$ ). Tumors were located in the gastric region in 96 cases and small intestinal area in 71 cases. According to NIH risk categories, 7 cases $(4.2 \%)$ belong to very low risk, followed by 48 cases $(28.7 \%)$ to low risk, 42 cases $(25.1 \%)$ to intermediate risk and 70 cases $(42 \%)$ to high risk. Cell types consist of 109 spindle cells $(65.2 \%), 24$ epithelioid cells $(14.6 \%)$ and 34 mixed types $(20.2 \%)$. There is high pleomorphism (moderate + severe) in 92 tumors $(51.7 \%)$ and low (mild) in 86 tumors (48.3\%). Baseline data bases revealed that large tumors tend to exhibit high tumor mitotic counts $(\mathrm{p}<0.001)$, non-spindle cell types $(\mathrm{p}=0.045)$ and high cell pleomorphism $(\mathrm{p}=0.007)$. Patients with small intestinal tumors had larger tumor sizes $(\mathrm{p}=0.002)$, higher male ratio $(\mathrm{p}=0.040)$, higher cell pleomorphism $(\mathrm{p}=0.002)$, and marginally earlier disease recurrence $(p=0.19)$ and shorter survival $(\mathrm{p}=0.09)$ than patients with gastric tumors. At the end of the follow-up, 45 out of 167 patients $(27.5 \%)$ had disease recurrence and 43 patients died of their tumors. The 1-, 3-, 5-year disease-free survival in each NIH risk category was $100,100,100 \%$ (very low risk); 100, 96, 91\% (low risk); 95, 89, 86\% (intermediate risk); and 74, 53, 47\% (high risk), respectively, which revealed a significant risk in the high risk group $(\mathrm{p}<0.001)$.

Immunostaining analyses. The positive immunoreactivity rates for panel antibodies were $81 \%$ for CD34, 52\% for SMA, $23 \%$ for S-100 and $3.5 \%$ for desmin. Small intestinal tumors exhibited a lower rate of CD34 ( $<<0.001)$, higher rates of SMA $(\mathrm{p}<0.001)$ and $\mathrm{S}-100(\mathrm{p}<0.001)$ immunoreactivity than gastric tumors (data not shown). These markers did not offer clinical or prognostic significance. Subsequently, the results of immunostaining for p53, p21/WAF1, Ki-67 and PCNA were analyzed. The immunoreactivity of these markers was calculated by the labeling index (LI, \%). The labeling index ranged from $0-83 \%$ for $\mathrm{p} 53,0-81 \%$ for $\mathrm{p} 21,0-33 \%$ for $\mathrm{Ki}-67$ and $12-92 \%$ for PCNA (Fig. 1A). Completely negative immunostaining $(\mathrm{LI}<1 \%)$ was found in $54.5 \%$ of $\mathrm{p} 53,25.8 \%$ of p21 and $44.3 \%$ of Ki-67 (Fig. 1B). Statistical analyses revealed that the LI of four markers strongly correlates with each other by the Spearman's rank correlation test $(\mathrm{p}<0.05)$ (Table II). We also found that the LI of all four markers 
Table II. Correlation between labeling index of molecular markers and pathological parameters.

\begin{tabular}{|c|c|c|c|c|c|c|c|}
\hline & Age & Tumor mitosis & Tumor size & $\mathrm{p} 53$ & p21/WAF1 & PCNA & $\mathrm{Ki}-67$ \\
\hline Age & & $\begin{aligned} \mathrm{CC} & =1.00 \\
\mathrm{p} & =0.695\end{aligned}$ & $\begin{aligned} \mathrm{CC} & =-0.043 \\
\mathrm{p} & =0.583\end{aligned}$ & $\begin{aligned} \mathrm{CC} & =-0.077 \\
\mathrm{p} & =0.322\end{aligned}$ & $\begin{array}{c}\mathrm{CC}=-0.039 \\
\mathrm{p}=0.616\end{array}$ & $\begin{array}{c}\mathrm{CC}=-0.048 \\
\mathrm{p}=0.534\end{array}$ & $\begin{aligned} \mathrm{CC} & =-0.084 \\
\mathrm{p} & =0.279\end{aligned}$ \\
\hline Tumor mitosis & $\begin{aligned} \mathrm{CC} & =1.00 \\
\mathrm{p} & =0.695\end{aligned}$ & & $\begin{array}{r}\mathrm{CC}=0.368 \\
\mathrm{p}<0.001^{\mathrm{a}}\end{array}$ & $\begin{aligned} \mathrm{CC} & =0.460 \\
\mathrm{p} & <0.001^{\mathrm{a}}\end{aligned}$ & $\begin{aligned} \mathrm{CC} & =0.154 \\
\mathrm{p} & =0.045\end{aligned}$ & $\begin{aligned} \mathrm{CC} & =0.570 \\
\mathrm{p} & <0.001^{\mathrm{a}}\end{aligned}$ & $\begin{aligned} \mathrm{CC} & =0.352 \\
\mathrm{p} & <0.001^{\mathrm{a}}\end{aligned}$ \\
\hline Tumor size & $\begin{array}{c}\mathrm{CC}=-0.043 \\
\mathrm{p}=0.583\end{array}$ & $\begin{aligned} \mathrm{CC} & =0.368 \\
\mathrm{p} & <0.001^{\mathrm{a}}\end{aligned}$ & & $\begin{aligned} \mathrm{CC} & =0.196 \\
\mathrm{p} & =0.010^{\mathrm{a}}\end{aligned}$ & $\begin{array}{c}\mathrm{CC}=-0.072 \\
\mathrm{p}=0.355\end{array}$ & $\begin{aligned} \mathrm{CC} & =0.225 \\
\mathrm{p} & =0.003^{\mathrm{a}}\end{aligned}$ & $\begin{aligned} \mathrm{CC} & =0.084 \\
\mathrm{p} & =0.283\end{aligned}$ \\
\hline p53 & $\begin{array}{c}\mathrm{CC}=-0.077 \\
\mathrm{p}=0.322\end{array}$ & $\begin{aligned} \mathrm{CC} & =0.460 \\
\mathrm{p} & <0.001^{\mathrm{a}}\end{aligned}$ & $\begin{aligned} \mathrm{CC} & =0.196 \\
\mathrm{p} & =0.010^{\mathrm{a}}\end{aligned}$ & & $\begin{aligned} \mathrm{CC} & =0.315 \\
\mathrm{p} & <0.001^{\mathrm{a}}\end{aligned}$ & $\begin{aligned} \mathrm{CC} & =0.370 \\
\mathrm{p} & <0.001^{\mathrm{a}}\end{aligned}$ & $\begin{aligned} \mathrm{CC} & =0.386 \\
\mathrm{p} & <0.001^{\mathrm{a}}\end{aligned}$ \\
\hline p21/WAF1 & $\begin{array}{c}\mathrm{CC}=-0.039 \\
\mathrm{p}=0.616\end{array}$ & $\begin{aligned} \mathrm{CC} & =0.154 \\
\mathrm{p} & =0.045\end{aligned}$ & $\begin{aligned} \mathrm{CC} & =-0.072 \\
\mathrm{p} & =0.355\end{aligned}$ & $\begin{aligned} \mathrm{CC} & =0.315 \\
\mathrm{p} & <0.001^{\mathrm{a}}\end{aligned}$ & & $\begin{aligned} \mathrm{CC} & =0.225 \\
\mathrm{p} & =0.003^{\mathrm{a}}\end{aligned}$ & $\begin{aligned} \mathrm{CC} & =0.249 \\
\mathrm{p} & =0.001^{\mathrm{a}}\end{aligned}$ \\
\hline PCNA & $\begin{array}{c}\mathrm{CC}=-0.048 \\
\mathrm{p}=0.534\end{array}$ & $\begin{aligned} \mathrm{CC} & =0.570 \\
\mathrm{p} & <0.001^{\mathrm{a}}\end{aligned}$ & $\begin{aligned} \mathrm{CC} & =0.225 \\
\mathrm{p} & =0.003^{\mathrm{a}}\end{aligned}$ & $\begin{aligned} \mathrm{CC} & =0.370 \\
\mathrm{p} & <0.001^{\mathrm{a}}\end{aligned}$ & $\begin{aligned} \mathrm{CC} & =0.225 \\
\mathrm{p} & =0.003^{\mathrm{a}}\end{aligned}$ & & $\begin{aligned} \mathrm{CC} & =0.325 \\
\mathrm{p} & <0.001^{\mathrm{a}}\end{aligned}$ \\
\hline Ki-67 & $\begin{aligned} \mathrm{CC} & =-0.084 \\
\mathrm{p} & =0.279\end{aligned}$ & $\begin{aligned} \mathrm{CC} & =0.352 \\
\mathrm{p} & <0.001^{\mathrm{a}}\end{aligned}$ & $\begin{aligned} \mathrm{CC} & =0.084 \\
\mathrm{p} & =0.283\end{aligned}$ & $\begin{aligned} & \mathrm{CC}=0.386 \\
& \mathrm{p}<0.001^{\mathrm{a}}\end{aligned}$ & $\begin{aligned} \mathrm{CC} & =0.249 \\
\mathrm{p} & =0.001^{\mathrm{a}}\end{aligned}$ & $\begin{aligned} & \mathrm{CC}=0.325 \\
& \mathrm{p}<0.001^{\mathrm{a}}\end{aligned}$ & \\
\hline
\end{tabular}

CC; correlation coefficient. ${ }^{a}$ Correlation is significant at the 0.05 level (2-tailed) by the Spearman's rank correlation test.

Table III. Correlation between nuclear labeling index and clinicopathological parameters of GISTs.

\begin{tabular}{|c|c|c|c|c|c|c|c|c|c|}
\hline & No. & p53 (\%) & $\mathrm{p}$ & p21/WAF1 (\%) & $\mathrm{p}$ & PCNA (\%) & $\mathrm{p}$ & Ki-67 (\%) & $\mathrm{p}$ \\
\hline Gender & & & $0.038^{\mathrm{a}}$ & & 0.310 & & $026^{\mathrm{a}}$ & & 0.065 \\
\hline Female & 86 & $9.6 \pm 18.7$ & & $16.9 \pm 20.3$ & & $69.7 \pm 13.2$ & & $2.8 \pm 5.8$ & \\
\hline Male & 81 & $15.4 \pm 22.3$ & & $19.1 \pm 19.2$ & & $72.3 \pm 15.1$ & & $4.1 \pm 6.5$ & \\
\hline Cell type & & & $0.012^{\mathrm{a}}$ & & $0.001^{\mathrm{a}}$ & & $<0.001^{\mathrm{a}}$ & & $0.012^{\mathrm{a}}$ \\
\hline Spindle & 109 & $9.3 \pm 17.4$ & & $14.3 \pm 18.1$ & & $69.0 \pm 13.7$ & & $2.52 \pm 5.23$ & \\
\hline Non-spindle & 58 & $18.4 \pm 25.0$ & & $24.7 \pm 20.9$ & & $74.8 \pm 14.4$ & & $5.10 \pm 7.41$ & \\
\hline Pleomorphism & & & $0.005^{\mathrm{a}}$ & & $0.010^{\mathrm{a}}$ & & $<0.001^{\mathrm{a}}$ & & 0.10 \\
\hline Low & 81 & $7.1 \pm 14.1$ & & $14.6 \pm 18.9$ & & $66.1 \pm 15.8$ & & $2.5 \pm 4.8$ & \\
\hline High & 86 & $17.4 \pm 24.4$ & & $21.0 \pm 20.0$ & & $75.6 \pm 10.6$ & & $4.2 \pm 7.2$ & \\
\hline NIH risk & & & $0.002^{\mathrm{b}}$ & & 0.094 & & $<0.001^{\mathrm{b}}$ & & $0.002^{\mathrm{b}}$ \\
\hline Very low & 7 & $0 \pm 0$ & & $3.0 \pm 4.16$ & & $63.7 \pm 23.6$ & & $1.0 \pm 1.15$ & \\
\hline Low & 48 & $5.3 \pm 10.5^{\mathrm{a}}$ & & $18.1 \pm 20.4$ & & $66.7 \pm 13.4$ & & $1.41 \pm 1.91$ & \\
\hline Intermediate & 42 & $9.0 \pm 16.6^{\mathrm{a}}$ & & $18.5 \pm 18.5$ & & $69.0 \pm 11.6$ & & $1.58 \pm 2.61$ & \\
\hline High & 70 & $20.6 \pm 25.8^{\mathrm{b}}$ & & $19.5 \pm 20.8$ & & $75.8 \pm 13.7$ & & $6.20 \pm 8.54$ & \\
\hline Tumor location & & & 0.20 & & 0.29 & & $<0.001^{\mathrm{a}}$ & & $<0.001^{\mathrm{a}}$ \\
\hline Stomach & 96 & $11.4 \pm 17.3$ & & $20.2 \pm 21.9$ & & $67.5 \pm 16.1$ & & $2.89 \pm 6.18$ & \\
\hline Small intestine & 71 & $13.8 \pm 24.6$ & & $14.8 \pm 15.8$ & & $75.7 \pm 9.20$ & & $4.19 \pm 6.22$ & \\
\hline
\end{tabular}

${ }^{\mathrm{a}}$ Mann-Whitney U test and ${ }^{\mathrm{b} K r u s k a l-W a l l i s ~} \mathrm{H}$ test. Statistically significant $(\mathrm{p}<0.05)$.

positively correlate to microscopic tumor mitotic counts $(\mathrm{p}<0.05)$. But only LI of p53 ( $<<0.011)$ and PCNA $(\mathrm{p}=0.003)$ positively correlate to tumor sizes (Table II). In addition, male patients tend to have increased p53 and PCNA LI $(\mathrm{p}<0.05)$ (Table III). Tumors with a non-spindle cell type exhibited a higher p53, p21/WAF1, PCNA and Ki-67 LI than the spindle cell type $(\mathrm{p}<0.05)$ (Table III). Tumors with higher cellular pleomorphism usually exhibit higher p53, p21/WAF1 and PCNA LI $(p<0.05)$ (Table III). Increased NIH risk also significantly correlated to increased p53 $(\mathrm{p}=0.002)$, PCNA 
A

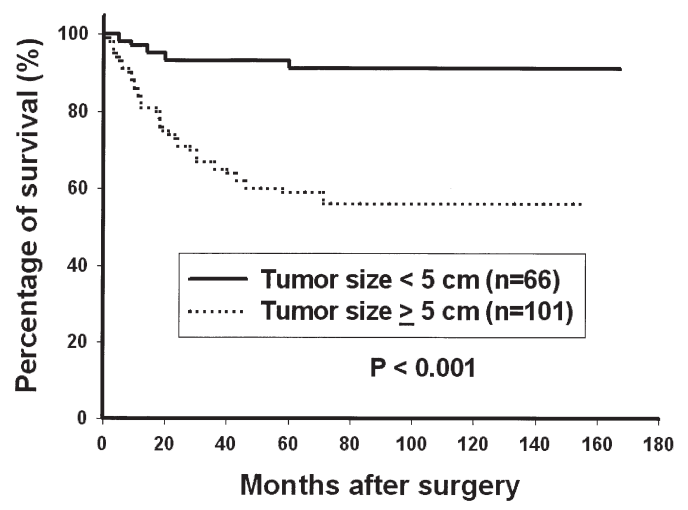

C

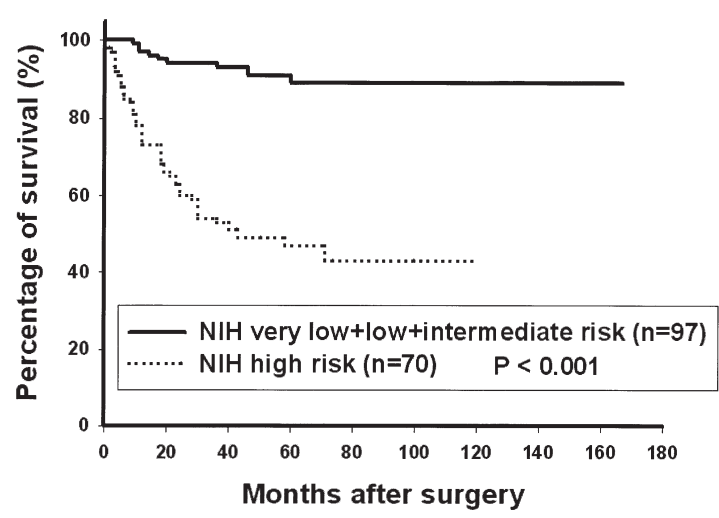

E

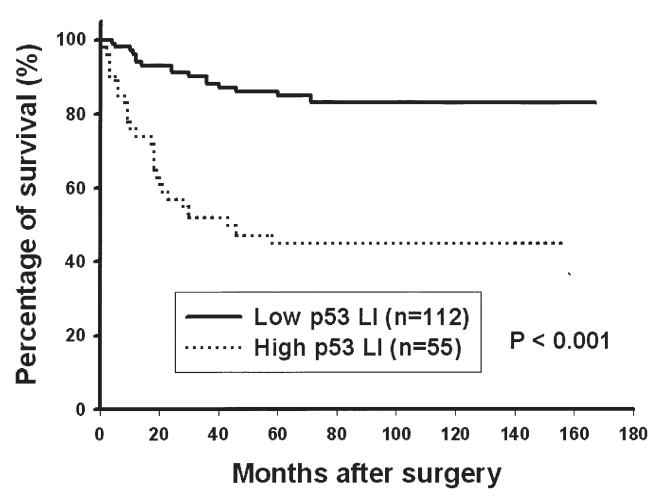

G

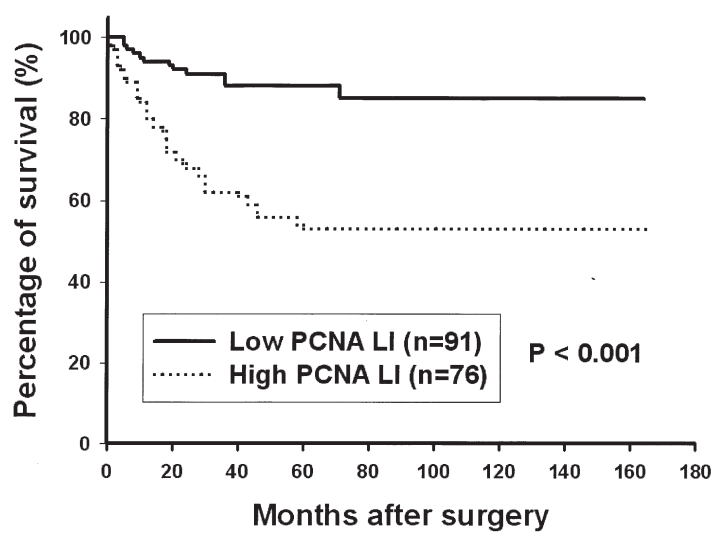

B

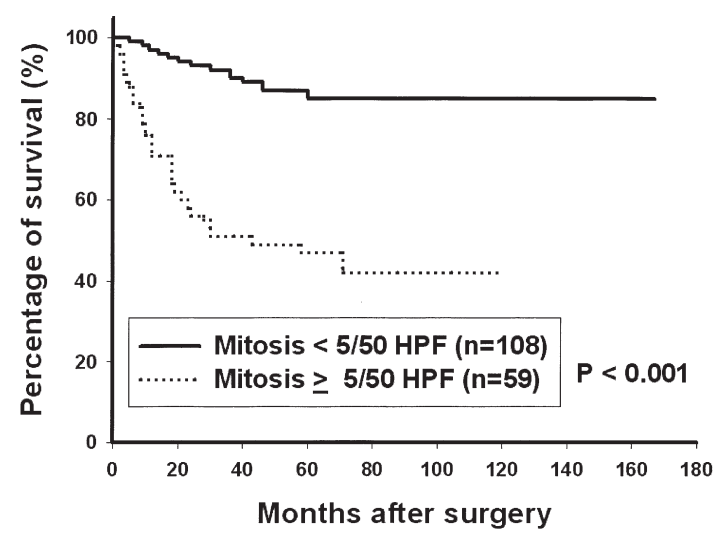

D
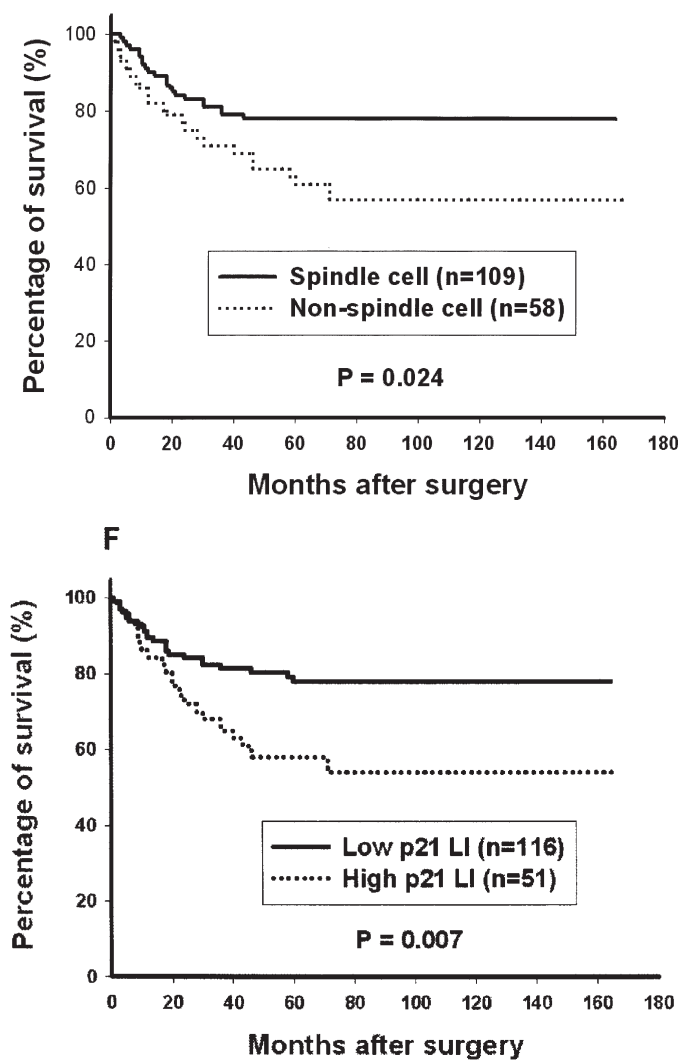

H

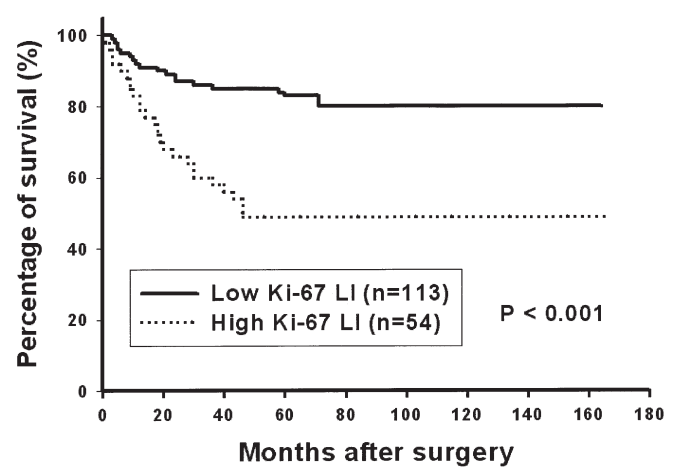

Figure 2. Kaplan-Meier analyses revealed that patients with a large tumor size (A); high mitotic activity (B); poor NIH risk (C); non-spindle cell type (D); high p53 LI (E); high p21/WAF1 LI (F); high PCNA LI (G), high Ki-67 LI (H) in their tumors had a shorter disease-free survival than comparison groups. The difference in survival was compared with the log-rank test. 
Table IV. Univariate and multivariate analyses for disease-free survival rates of individual parameters of GIST patients.

\begin{tabular}{|c|c|c|c|c|c|c|}
\hline & \multicolumn{3}{|c|}{ Univariate } & \multicolumn{3}{|c|}{ Univariate } \\
\hline & Risk & $95 \% \mathrm{CI}$ & $\mathrm{p}$ & Risk & $95 \% \mathrm{CI}$ & $\mathrm{p}$ \\
\hline Age & 1.060 & $0.59-1.91$ & NS $(0.83)$ & - & - & - \\
\hline Gender & 1.740 & $1.74-3.16$ & NS $(0.063)$ & - & - & - \\
\hline Tumor size & 6.460 & $2.54-16.3$ & $<0.001^{\mathrm{a}}$ & 2.76 & $1.02-7.47$ & $0.028^{\mathrm{a}}$ \\
\hline Tumor mitoses & 5.660 & $3.01-10.6$ & $<0.001^{\mathrm{a}}$ & - & - & 0.42 \\
\hline NIH risk category & 7.670 & $3.68-15.9$ & $<0.001^{\mathrm{a}}$ & 4.58 & $4.58-10.1$ & $<0.001^{\mathrm{a}}$ \\
\hline Tumor location & 1.580 & $0.88-2.84$ & NS $(0.12)$ & - & - & - \\
\hline Cell type & 1.950 & $1.09-3.51$ & $0.024^{\mathrm{a}}$ & - & - & 0.90 \\
\hline Pleomorphism & 1.310 & $0.73-2.36$ & NS $(0.37)$ & - & - & - \\
\hline p53 & 4.890 & $2.65-9.03$ & $<0.001^{\mathrm{a}}$ & 3.09 & $1.65-5.79$ & $<0.001^{\mathrm{a}}$ \\
\hline p21/WAF1 & 2.186 & $1.21-3.93$ & $0.007^{\mathrm{a}}$ & 2.11 & $1.16-3.86$ & $0.017^{\mathrm{a}}$ \\
\hline $\mathrm{Ki}-67$ & 1.220 & $3.92-6.33$ & $<0.001^{\mathrm{a}}$ & - & - & 0.14 \\
\hline PCNA & 4.470 & $2.26-8.83$ & $<0.001^{\mathrm{a}}$ & - & - & 0.17 \\
\hline CD34 & 3.290 & $0.32-14.3$ & NS (0.29) & - & - & - \\
\hline SMA & 1.240 & $0.47-3.28$ & NS (0.67) & - & - & - \\
\hline Desmin & 0.710 & $0.20-3.64$ & NS (0.57) & - & - & - \\
\hline S-100 & 2.240 & $0.65-1.48$ & NS $(0.21)$ & - & - & - \\
\hline
\end{tabular}

Age, $\geq 60$ or $<60$ years; gender, male or female; tumor size, $\geq 5$ or $<5 \mathrm{~cm}$; mitoses, $\geq 5$ or $<5 / 50$ HPF; NIH risk categories, poor or very low + low + intermediate; tumor location, stomach or small intestine; cell type, spindle or non-spindle; pleomorphism, high or low+moderate; p53, high or low; p21/WAF1, high or low; Ki67, high or low, PCNA, high or low; CD34, positive or negative; SMA, positive or negative; desmin, positive or negative; S-100, positive or negative. Statistically significant $\left({ }^{\mathrm{a}} \mathrm{p}<0.05\right)$.

$(\mathrm{p}<0.001)$ Ki-67 ( $\mathrm{p}=0.002)$ and p21/WAF1 ( $=0.094)$ expression (Table III). Tumors located in the small bowel are found to have more proliferating index (higher PCNA and Ki-67) than tumors in the stomach region, although there is no difference in cell cycle regulators (p53 and p21/WAF1) (Table III). These may explain why patients with small bowel tumors had relatively earlier disease recurrence and shorter survival.

Survival analysis. We divided the nuclear LI of p21/WAF1, p53, Ki-67 and PCNA into two groups as high or low expression by the ROC curve according to reference of disease recurrence. The cut-off levels are $7.9 \%$ for $\mathrm{p} 53,16.5 \%$ for p21/WAF1, 4.5\% for Ki-67 and 76\% for PCNA. Univariate survival analysis revealed that patients with large tumor size ( $\geq 5 \mathrm{~cm}, \mathrm{p}<0.001$, Fig. 2A), high tumor mitosis ( $\geq 5 / 50 \mathrm{HPF}$, $\mathrm{p}<0.001$, Fig. 2B), high NIH risk $(\mathrm{p}<0.001$, Fig. $2 \mathrm{C})$, nonspindle cell type ( $p=0.024$, Fig. 2D), high p53 LI $(p<0.001$, Fig. 2E), high p21/WAF1 LI (p=0.007, Fig. 2F), high PCNA LI (p<0.001, Fig. 2G) and high Ki-67 LI (p<0.001, Fig. 2H) were prognostic factors for poor disease-free survival. Further multivariate analysis by Cox's proportional hazard model revealed that only tumor size, NIH risk, p53 and p21/WAF1 LI were independent prognostic factors for disease-free survival of GIST patients after operation (Table IV). These four factors also independently predict patients' overall survival after recurrence (data not shown).

\section{Discussion}

Several studies have suggested that tumor size and mitotic count, alone or in combination (16) and Ki-67 (14-17) or
PCNA $(15,16)$ proliferative index, tumor suppressor gene p53 (17-19) and p21/WAF1 $(18,27)$ were useful in predicting the clinical behavior of GISTs. However, the varying conclusions drawn from previous studies were matched by their deficiency: relatively small case numbers studied, and many studies were done before KIT detection was available (especially for PCNA). The distinction between GISTs and pure neural or smooth muscle tumors is important as the latter may portend a better prognosis (16). There is also a lack of linear correlation of the p53/p21/PCNA pathway in the previous literatures.

To overcome these deficiencies, we conducted a large case review of 167 KIT-positive GISTs which were located in the gastric and small intestinal areas. We also adopted a linear linkage of the p53/p21/PCNA pathway for analysis. Through a combination of these molecular markers and other clinicopathological factors, the results may shed a light to elucidate the clinical behavior of GISTs. We provided prognostic evidence of the two cell cycle regulators p53 and p21/WAF1, their target PCNA and well-known proliferating marker Ki-67 in GISTs. The expression of each single gene closely correlates with each other. Each single gene had a diagnostic value of malignant potential (positive correlation to tumor mitosis) of GISTs. These findings suggested that high proliferating states and a high p53 and p21/WAF1 expression occur in a portion of GISTs (non-spindle cell type, high cell pleomorphism) and may constitute poor prognosis. In addition to traditional factors such as NIH risk categories and tumor size, p53/p21/PCNA cell cycle regulators can help to predict the prognosis of disease recurrence and survival for GIST patients. 
PCNA is a nuclear protein, which is closely related to the cell cycle regulation as it is an auxiliary molecule for DNA polymerase- $\delta(28)$. It is also an auxiliary protein present during G1-late phase and S phase. The tumor suppressor gene (p53) has an important function in DNA repair and in the regulation of apoptosis. Mutations of p53 were described in malignant tumors and can be the cause of the alterations of this balance. The correlation between the p53 and PCNA expression in other malignancies has been reported (29). In general, p53 positivity correlated to an increased PCNA labeling index in neoplasia and represented advanced disease states and a poor outcome. We found a strong correlation between the p53 and PCNA index in GISTs, which was comparative with previous studies. The cyclin-dependent kinase inhibitor p21/WAF1 is regulated by $\mathrm{p} 53$-dependent pathways, therefore, $\mathrm{p} 21 / \mathrm{WAF} 1$ binds with PCNA and inhibits the action of PCNA (30). Overexpression of p53 on immunostaining (mostly p53 mutation) may disturb this pathway and trigger PCNA activity, thereby promoting cancer cell proliferation.

$\mathrm{P} 21 / \mathrm{WAF} 1$ is reported to inhibit proliferation both in vitro and in vivo and the introduction of p21/WAF1 expression constructs into normal (31) or tumor cell lines (24) resulting in cell cycle arrest in G1 and mediates G2 arrest (32). A reduced p21/WAF1 expression is frequently observed in other cancers, either in mRNA $(33,34)$ or at the protein level $(35,36)$. In hepatocellular carcinoma with a mutant p53 gene, the p21/ WAF1 mRNA expression levels were significantly lower than those of corresponding non-cancerous liver tissues, whereas the p21/WAF1 mRNA expression levels of HCCs with the wild-type p53 gene were not significantly different from the levels in the corresponding non-cancerous tissues $(34,37)$. While p21/WAF1 usually acts as a negative regulator of the cell cycle, increase of the $\mathrm{p} 21 / \mathrm{WAF} 1$ expression by mitogenic stimuli was observed by several investigators $(25,38)$. In this present study, a significantly positive correlation between the p21/WAF1 and PCNA expression is noted (Table II). The possible explanation of the overexpression of p21/WAF1 was in order to control the abnormal cell cycle progression and to suppress replication of the tumor cells, which was demonstrated that ectopic p21/WAF1 introduction suppressed the growth of cancer lines from an in vitro study (39). It implies that when the proliferating tumor cells contain increased PCNA, more p21/WAF1 may be required to bind PCNA and then to inhibit the activity of PCNA (40). Under high proliferating states of tumor, an increased $\mathrm{p} 21 / \mathrm{WAF} 1$ is just a reactive event to inhibit cell growth, as found in our study. Mutation does not play a key role in causing an overexpression of p21/ WAF1 in cancers $(30,41)$. Taken together, an increased expression of p21/WAF1 in different types of cancers is regulated through another p53-independent pathway in contrast to a reduced $\mathrm{p} 21 / \mathrm{WAF} 1$ expression through a p53-dependent pathway. The above may explain the reason for the parallel overexpression of p21/WAF1 and p53 in this study.

In studies of gastrointestinal smooth muscle tumors/GISTs, increased PCNA and Ki-67 expressions were usually considered to be poor prognostic markers (14-17). However, p53 positivity was considered to be non-prognostic $(42,43)$ or as a poor prognostic marker in different studies $(17,44)$. In contrast, p21/WAF1 was not reported to be prognostic in GISTs before $(18,27)$. We found that the $\mathrm{p} 53$ and $\mathrm{p} 21 / \mathrm{WAF} 1$ labeling index strongly and positively related to an increased mitotic index (Ki-67, PCNA and tumor mitotic count) and were independent prognostic factors for GIST patients after resection. The possible reason for the discrepancy between our and other studies may result from a different definition of the positivity of p53 or p21/WAF1 expression (usually defined by cut-off level as 5 or $10 \%$ in other studies). Therefore, we adopted a pure labeling index for statistical analysis among grouping comparison (as in Tables II and III) rather than using simple positive or negative grouping. We also use cut-off levels by the ROC curve instead of the routine 5 or $10 \%$ (in other studies) for survival comparison (as in Table IV). Based on these, the bias of statistics can be minimized and the prediction of prognosis can be more accurate and exact. It may provide another reference to deal with the immunohistochemical scoring of p53 or p21/WAF1 in the future.

In conclusion, we demonstrated evidence of the p53/ p21/PCNA pathway linkage and verified the significant relationship between these markers and clinicopathological factors in GISTs. Based on the large sample size and long-term follow-up, we also found that the $\mathrm{p} 21 / \mathrm{WAF} 1$ expression in GISTs serves as an independent survival prognostic factor which is a novel finding. Increased expression of p53 and p21/WAF1 is an unfavorable sign in GISTs. Abnormalities of the p53/p21 pathway may lead to increased proliferating states of GISTs, thereby triggering pathogenesis and the progression of GISTs.

\section{References}

1. Rudolph P, Chiaravalli AM, Pauser U, et al: Gastrointestinal mesenchymal tumors - immunophenotypic classification and survival analysis. Virchows Arch 441: 238-248, 2002.

2. Lasota J, Jasinski M, Sarlomo-Rikala M and Miettinen M: Mutations in exon 11 of c-Kit occur preferentially in malignant versus benign gastrointestinal stromal tumors and do not occur in leiomyomas or leiomyosarcomas. Am J Pathol 154: 53-60, 1999.

3. El-Rifai W, Sarlomo-Rikala M, Andersson LC, Knuutila S and Miettinen M: DNA sequence copy number changes in gastrointestinal stromal tumors: tumor progression and prognostic significance. Cancer Res 60: 3899-3903, 2000.

4. Miettinen M, Sobin LH and Lasota J: Gastrointestinal stromal tumors of the stomach: a clinicopathologic, immunohistochemical and molecular genetic study of 1765 cases with longterm follow-up. Am J Surg Pathol 29: 52-68, 2005.

5. Hu TH, Lin JW, Changchien CS, Liu SY, Chiou SS and Chuang JH: Immunohistochemical analyses of gastric stromal tumors in Taiwanese. J Formos Med Assoc 102: 707-714, 2003.

6. Fletcher CD, Berman JJ, Corless C, et al: Diagnosis of gastrointestinal stromal tumors: A consensus approach. Hum Pathol 33 459-465, 2002.

7. Ueyama T, Guo KJ, Hashimoto H, Daimaru Y and Enjoji M: A clinicopathologic and immunohistochemical study of gastrointestinal stromal tumors. Cancer 69: 947-955, 1992.

8. Newman PL, Wadden C and Fletcher CD: Gastrointestinal stromal tumors: correlation of immunophenotype with clinicopathological features. J Pathol 164: 107-117, 1991.

9. Franquemont DW and Frierson HF Jr: Muscle differentiation and clinicopathologic features of gastrointestinal stromal tumors. Am J Surg Pathol 16: 947-954, 1992.

10. Evans HL: Smooth muscle tumors of the gastrointestinal tract. A study of 56 cases followed for a minimum of 10 years. Cancer 56: 2242-2250, 1985.

11. Ito Y, Matsuura N, Sakon M, et al: Expression and prognostic roles of the G1-S modulators in hepatocellular carcinoma: p27 independently predicts the recurrence. Hepatology 30: 90-99, 1999.

12. Ernst SI, Hubbs AE, Przygodzki RM, Emory TS, Sobin LH and O'Leary TJ: KIT mutation portends poor prognosis in gastrointestinal stromal/smooth muscle tumors. Lab Invest 78 : 1633-1636, 1998. 
13. Fletcher CD: Clinicopathologic correlations in gastrointestinal stromal tumors. Hum Pathol 33: 455, 2002.

14. Nakamura N, Yamamoto H, Yao T, et al: Prognostic significance of expressions of cell-cycle regulatory proteins in gastrointestinal stromal tumor and the relevance of the risk grade. Hum Pathol 36: 828-837, 2005.

15. Carrillo R, Candia A, Rodriguez-Peralto JL and Caz V: Prognostic significance of DNA ploidy and proliferative index (MIB-1 index) in gastrointestinal stromal tumors. Hum Pathol 28: 160-165, 1997.

16. Franquemont DW: Differentiation and risk assessment of gastrointestinal stromal tumors. Am J Clin Pathol 103: 41-47, 1995.

17. Wong NA, Young R, Malcomson RD, et al: Prognostic indicators for gastrointestinal stromal tumors: a clinicopathological and immunohistochemical study of 108 resected cases of the stomach. Histopathology 43: 118-126, 2003.

18. Sabah M, Cummins R, Leader M and Kay E: Altered expression of cell cycle regulatory proteins in gastrointestinal stromal tumors: markers with potential prognostic implications. Hum Pathol 37: 648-655, 2006.

19. Wang X, Mori I, Tang W, et al: Helpful parameter for malignant potential of gastrointestinal stromal tumors (GIST). Jpn J Clin Oncol 32: 347-351, 2002.

20. Cayrol C, Knibiehler M and Ducommun B: p21 binding to PCNA causes G1 and G2 cell cycle arrest in p53-deficient cells. Oncogene 16: 311-320, 1998.

21. Pagano M, Theodoras AM, Tam SW and Draetta GF: Cyclin D1-mediated inhibition of repair and replicative DNA synthesis in human fibroblasts. Genes Dev 8: 1627-1639, 1994.

22. Macleod KF, Sherry N, Hannon G, et al: p53-dependent and independent expression of p21 during cell growth, differentiation and DNA damage. Genes Dev 9: 935-944, 1995.

23. Xiong Y, Hannon GJ, Zhang H, Casso D, Kobayashi R and Beach D: p21 is a universal inhibitor of cyclin kinases. Nature 366: 701-704, 1993.

24. el-Deiry WS, Tokino T, Velculescu VE, et al: WAF1, a potential mediator of p53 tumor suppression. Cell 75: 817-825, 1993.

25. Michieli P, Chedid M, Lin D, Pierce JH, Mercer WE and Givol D: Induction of WAF1/CIP1 by a p53-independent pathway. Cancer Res 54: 3391-3395, 1994.

26. Parker SB, Eichele G, Zhang P, et al: p53-independent expression of p21Cip 1 in muscle and other terminally differentiating cells. Science 267: 1024-1027, 1995.

27. Nemoto Y, Mikami T, Hana K, et al: Correlation of enhanced cell turnover with prognosis of gastrointestinal stromal tumors of the stomach: relevance of cellularity and p27kip1. Pathol Int 56: 724-731, 2006.

28. Bravo R, Frank R, Blundell PA and Macdonald-Bravo H: Cyclin/PCNA is the auxiliary protein of DNA polymerase-delta. Nature 326: 515-517, 1987.

29. Russell M, Berardi P, Gong W and Riabowol K: Grow-ING, Age-ING and Die-ING: ING proteins link cancer, senescence and apoptosis. Exp Cell Res 312: 951-961, 2006.
30. Qin LF, Ng IO, Fan ST and Ng M: p21/WAF1, p53 and PCNA expression and p53 mutation status in hepatocellular carcinoma. Int J Cancer 79: 424-428, 1998.

31. Harper JW, Adami GR, Wei N, Keyomarsi K and Elledge SJ: The p 21 Cdk-interacting protein Cip1 is a potent inhibitor of G1 cyclin-dependent kinases. Cell 75: 805-816, 1993.

32. Dulic V, Stein GH, Far DF and Reed SI: Nuclear accumulation of p21Cip1 at the onset of mitosis: a role at the G2/M-phase transition. Mol Cell Bio 18: 546-557, 1998.

33. Kobayashi S, Matsushita K, Saigo K, et al: P21WAF1/CIP1 messenger RNA expression in hepatitis $\mathrm{B}, \mathrm{C}$ virus-infected human hepatocellular carcinoma tissues. Cancer 91: 2096-2103, 2001.

34. Hui AM, Kanai Y, Sakamoto M, Tsuda H and Hirohashi S: Reduced p21(WAF1/CIP1) expression and p53 mutation in hepatocellular carcinomas. Hepatology 25: 575-579, 1997.

35. Shi YZ, Hui AM, Takayama T, Li X, Cui X and Makuuchi M: Reduced $\mathrm{p} 21(\mathrm{WAF} 1 / \mathrm{CIP} 1)$ protein expression is predominantly related to altered p53 in hepatocellular carcinomas. Br J Cancer 83: $50-55,2000$

36. Qin LF and Ng IO: Expression of p27(KIP1) and p21(WAF1/ CIP1) in primary hepatocellular carcinoma: clinicopathologic correlation and survival analysis. Hum Pathol 32: 778-784, 2001.

37. Crary GS and Albrecht JH: Expression of cyclin-dependent kinase inhibitor p21 in human liver. Hepatology 28: 738-743, 1998.

38. Halaban R, Cheng E, Zhang Y, Mandigo CE and Miglarese MR: Release of cell cycle constraints in mouse melanocytes by overexpressed mutant E2F1E132, but not by deletion of p16INK4A or p21WAF1/CIP1. Oncogene 16: 2489-2501, 1998.

39. Qin LF and Ng IO: Exogenous expression of p21(WAF1/CIP1) exerts cell growth inhibition and enhances sensitivity to cisplatin in hepatoma cells. Cancer Lett 172: 7-15, 2001.

40. Ng IO, Lai EC, Fan ST, Ng M, Chan AS and So MK: Prognostic significance of proliferating cell nuclear antigen expression in hepatocellular carcinoma. Cancer 73: 2268-2274, 1994.

41. Gao X, Chen YQ, Wu N, et al: Somatic mutations of the WAF1/CIP1 gene in primary prostate cancer. Oncogene 11: 1395-1398, 1995.

42. Panizo-Santos A, Sola I, Vega F, et al: Predicting Metastatic Risk of Gastrointestinal Stromal Tumors: Role of Cell Proliferation and Cell Cycle Regulatory Proteins. Int J Surg Pathol 8: 133-144, 2000.

43. Suster S, Fisher C and Moran CA: Expression of bcl-2 oncoprotein in benign and malignant spindle cell tumors of soft tissue, skin, serosal surfaces and gastrointestinal tract. Am J Surg Pathol 22: 863-872, 1998.

44. Feakins RM: The expression of p53 and bcl-2 in gastrointestinal stromal tumors is associated with anatomical site and p53 expression is associated with grade and clinical outcome. Histopathology 46: 270-279, 2005. 